A N N A L E S Annales de Bretagne et des Pays de l'Ouest

\title{
Les Routes européennes du savoir
}

Sébastien Jahan

\section{OpenEdition}

\section{Journals}

Édition électronique

URL : http://journals.openedition.org/abpo/2420

DOI : $10.4000 / a b p o .2420$

ISBN : 978-2-7535-2129-2

ISSN : 2108-6443

\section{Éditeur}

Presses universitaires de Rennes

Édition imprimée

Date de publication : 30 juin 2012

Pagination : 202-204

ISBN : 978-2-7535-2127-8

ISSN : 0399-0826

Référence électronique

Sébastien Jahan, "Les Routes européennes du savoir », Annales de Bretagne et des Pays de l'Ouest [En ligne], 119-2 | 2012, mis en ligne le 30 juin 2012, consulté le 09 juillet 2020. URL : http:// journals.openedition.org/abpo/2420

Ce document a été généré automatiquement le 9 juillet 2020

(c) Presses universitaires de Rennes 


\title{
Les Routes européennes du savoir
}

\author{
Sébastien Jahan
}

\section{RÉFÉRENCE}

HIERNARD, Jean, TURREL, Denise et DELMAS-RIGOUTSOS, Yannis, Les Routes européennes du savoir. Vita Peregrinatio (fin du Moyen-Âge-XVII siècle), Paris, Les Indes savantes, 2011, 343 p. (ISBN 978-2-84654-269-2).

1 Ce recueil d'articles est d'abord un hommage aux recherches que Jean Hiernard, professeur d'histoire ancienne à l'université de Poitiers, a consacré à la mobilité étudiante de la première modernité. Ce spécialiste reconnu de numismatique celtique et romaine se passionne aussi depuis les années 1990 pour les circulations entre le Poitou et l'espace germanique aux $\mathrm{XVI}^{\mathrm{e}}$ et $\mathrm{XVII}^{\mathrm{e}}$ siècles. Parti sur les traces des mercenaires allemands engagés dans les guerres de religion (à travers l'étude des trésors monétaires), il en est venu à s'intéresser aux pérégrinations savantes, à la faveur de la découverte, dans le récit de voyage d'un étudiant silésien de passage à Poitiers, de relevés épigraphiques datant de l'époque romaine. C'est donc lui aussi en passeur de frontières - académiques celles-là - que J. Hiernard traque et examine depuis lors toutes les sources susceptibles de témoigner de la présence à Poitiers d'enseignants et d'élèves originaires du nord ou du centre de l'Europe (Pays-Bas, Provinces-Unies, Empire germanique). Tout en dépouillant les registres des gradués en droit conservés depuis 1575, il s'est mis en quête des alba amicorum, ces " livres d'amis " apparus au milieu $\mathrm{du} \mathrm{xvI}^{\mathrm{e}}$ siècle dans lesquels les étudiants itinérants (très majoritairement des sujets du Saint-Empire de confession réformée) « demandaient à leurs maîtres ou à leurs condisciples d'écrire quelques réflexions ou pensées édifiantes" (p.61). Un travail de fourmi qui l'a conduit également à consulter les registres des nations germaniques d'autres universités françaises (comme Orléans) qui font parfois état du passage à Poitiers de certains de leurs étudiants. Croisées entre elles, ces séries documentaires sont en outre confrontées avec d'autres sources plus ponctuelles, comme l'étonnante gravure du peintre de la cour de Rodolphe II, Joris 
Hoefnagel, natif d'Anvers, qui se met en scène en 1561 avec quatre de ses camarades, occupés à inciser leurs noms sur le dolmen de la Pierre Levée à Poitiers.

2 Le résultat de ces patientes investigations figure dans ce beau livre, réunissant neuf textes de J. Hiernard, pour la plupart déjà publiés dans des revues d'histoire régionale ou des actes de colloque. En dépit d'inévitables répétitions d'une contribution à une autre, l'idée de rassembler ici ce savoir clairsemé s'avère particulièrement fructueuse, tant les échos et les passerelles sont constants entre portraits collectifs et analyses de parcours individuels. Le tout est étayé par une prodigieuse érudition qu'illustrent la densité et la variété des références bibliographiques de l'auteur, aussi bien en français qu'en langues étrangères. Mais, dans l'esprit de ses concepteurs, l'ambition de l'ouvrage ne se borne pas à compiler le fruit d'une décennie de recherches. Cette publication pose aussi les jalons d'une enquête en devenir. J. Hiernard n'exclut d'abord pas la découverte de nouvelles sources qui viendraient compléter le corpus de Germani ayant fréquenté les facultés poitevines. Il ouvre par ailleurs le chantier d'une reconstitution du mouvement migratoire inverse, celui des étudiants poitevins, aunisiens ou saintongeais qui empruntèrent l'iter hollandicum ou l'iter germanicum, laissant ainsi entrevoir l'existence d'échanges privilégiés entre universités. Toute la première partie de l'ouvrage aboutit surtout à inscrire les travaux de J. Hiernard dans le cadre de l'élaboration de bases de données prosopographiques informatisées. Dans le sillage du Repertorium Academicum Germanicum (Université de Berne) visant à recenser tous les gradués du Saint-Empire entre 1250 et 1550, ou encore du fascinant Irish in Europe Project (Université Nationale d'Irlande, Maynooth), plate-forme virtuelle de recherche «apte à accueillir [...] toutes les bases de données liées à la migration irlandaise vers l'Europe", J. Hiernard, Denise Turrel et Yannis Delmas ont créé un répertoire académique poitevin en ligne (le « RAP ») qui, à l'époque de la publication de l'ouvrage, comptait déjà 4000 noms de gradués en droit et dont on peut suivre l'évolution sur le site [http://repertorium.projets.univ-poitiers.fr]. L'idée est d'autant plus séduisante qu'elle souhaite s'intégrer dans un « réseau pan-européen » qui faciliterait la convergence des informations recueillies dans le champ de la mobilité académique, à l'échelle du continent.

3 Le livre manque malgré tout, selon nous, d'une mise en perspective du cas poitevin qui nous permettrait de prendre une première mesure de la place qu'occupait cette université sur les « routes du savoir ", à l'époque considérée. Des indices sont livrés ça et là, sur l'attrait des cursus de droit romain pour les sujets de l'Empire germanique dont c'était en quelque sorte le droit naturel. Le rôle de certains enseignements prestigieux, du nomadisme des professeurs (qui circulent avec leurs élèves), de l'implantation du protestantisme dans le monde de la judicature poitevine, ou encore de la qualité de la vie locale est également effleuré. Et l'on comprend aussi que les soubresauts $\mathrm{du}$ contexte politico-diplomatique interfèrent avec une certaine stratification chronologique des nationalités représentées. Néanmoins l'ensemble appelle déjà, nous semble-t-il, une première ébauche synthétique qui mette en évidence les tropismes et les flux caractéristiques, avec leurs ruptures et continuités, les différents facteurs de la mobilité, les réseaux relationnels qui la permettent et qui en surgissent, etc. La transcription en introduction de la brillante conférence de Willem Frijhoff dessinant les grandes étapes de l'histoire du "voyage éducatif » comme "patrimoine immatériel de l'Europe ", ne pallie malheureusement point ce défaut d'un livre kaléidoscopique et au cheminement joliment erratique. 